\title{
A modified digital hysteresis and artificial neural network (ANN) algorithms in single phase shunt active power filter control
}

\begin{abstract}
Suppliers of electricity and their consumers have attained a peak stage of concern regarding the quality of electric power nowadays, with current harmonics concise injection activities looms the power networks as certain loads (principally nonlinear loads) are applied on to it. With active power filter (APF) wide knowledge and sophistication in this regard, a high performance extraction algorithm coupled with a fast switching technique must be developed in utilizing this device optimum potential. This paper introduces a new effective algorithms for the compensation of this ill effects in the power networks namely the digital hysteresis algorithm with a modification by bandwidth absence in the switching analysis (called bandless digital hysteresis algorithm) and a modified artificial neural network responsible to detect and generate the necessary compensation signal injected on to the power networks by the harmonic agents. The proposed scheme is achieved via simulation studies (under MATLAB SIMULINK environment) and effectives results obtained are discussed to verify its performance.
\end{abstract}

Keyword: Harmonics; Bandless digital hysteresis; Neural network; Shunt active power filter; Total harmonic distortion; Power factor 